\title{
Pt-Pd nanoelectrocatalyst of ultralow Pt content for the oxidation of formic acid: Towards tuning the reaction pathway
}

\author{
SOUROV GHOSH and C RETNA RAJ* \\ Department of Chemistry, Indian Institute of Technology Kharagpur, Kharagpur 721 302, India \\ e-mail: crraj@chem.iitkgp.ernet.in
}

MS received 21 July 2014; revised 07 December 2014; accepted 09 December 2014

\begin{abstract}
Synthesis of highly efficient functional electrocatalyst that favours the electrochemical oxidation of formic acid via CO-free dehydrogenation pathway is required for direct formic acid fuel cells. Traditional catalysts favour the dehydration pathway involving the generation of poisonous $\mathrm{CO}$. Herein we demonstrate the superior electrocatalytic performance of Pt-Pd bimetallic nanoelectrocatalyst of ultralow Pt content and tuning the reaction pathway by controlling the Pt content. Bimetallic nanoparticles of $\mathrm{Pt}_{4} \mathrm{Pd}_{96}, \mathrm{Pt}_{7} \mathrm{Pd}_{93}$ and $\mathrm{Pt}_{47} \mathrm{Pd}_{53}$ compositions are synthesized by electrochemical co-deposition method in aqueous solution. The nanoparticles of ultralow $\mathrm{Pt}$ content, $\mathrm{Pt}_{4} \mathrm{Pd}_{96}$, favour the $\mathrm{CO}$-free dehydrogenation pathway for formic acid oxidation with an onset potential of $0 \mathrm{~V}$ (SHE) whereas the $\mathrm{Pt}_{47} \mathrm{Pd}_{53}$ nanoparticles favour the dehydration pathway involving the formation of $\mathrm{CO}$ at high positive potential. The Pt content of the bimetallic nanoparticles actually controls the oxidation peak potential and catalytic activity. Significant negative shift $(\sim 350 \mathrm{mV})$ in the oxidation peak potential and remarkable enhancement in the current density (2.6 times) are observed for $\mathrm{Pt}_{4} \mathrm{Pd}_{96}$ nanoparticles with respect to $\mathrm{Pt}_{47} \mathrm{Pd}_{53}$. The absence of three adjacent $\mathrm{Pt}$ and $\mathrm{Pd}$ atoms could be the reason for the suppression of $\mathrm{CO}$ pathway. The electrochemical impedance measurements indirectly support the $\mathrm{CO}$-free pathway for the formic acid oxidation on $\mathrm{Pt}_{4} \mathrm{Pd}_{96}$ nanoparticles.
\end{abstract}

Keywords. Bimetallic nanoparticles; electrochemical deposition; formic acid oxidation; dehydrogenation; electrocatalysis.

\section{Introduction}

The small organic molecule-based polymer electrolyte membrane (PEM) fuel cell attracts immense attention due to their ease of operation at room temperature and light weight. Among the direct liquid fuel cells, formic acid fuel cell (DFAFC) has several advantages: (i) the theoretical cell voltage of DFAFC is higher $(1.45 \mathrm{~V})$ than that of direct methanol fuel cell (DMFC) $(1.18 \mathrm{~V})$ at room temperature, ${ }^{1-4}$ (ii) formic acid crossover flux through Nafion ${ }^{\circledR}$ membrane is two-orders magnitude lower than methanol, ${ }^{2}$ enabling the use of concentrated formic acid $(\sim 80 \%)$ to achieve high energy density compared to DMFC, ${ }^{3}$ (iii) it is non-toxic and has faster oxidation kinetics on anode catalysts with respect to methanol. In contrast to methanol oxidation, the complete oxidation of formic acid does not require water at the anode, allowing the use of concentrated formic acid. ${ }^{4}$ Formic acid can undergo oxidation in two different pathways on metal surface, viz., dehydration and dehydrogenation pathways (figure 1). In dehydrogenation pathway, the direct oxidation of formic acid produces $\mathrm{CO}_{2}$. On the other hand, dehydration pathway

\footnotetext{
*For correspondence
}

witnesses the formation of adsorbed intermediate $\mathrm{CO}_{\text {ads }}$ on the metal surface and retards the oxidation kinetics. Recently, another parallel pathway involving the formation weakly adsorbed intermediate $\mathrm{HCOO}_{\mathrm{ads}}$ has also been proposed. ${ }^{5}$ The pathway for the oxidation of formic acid depends on the nature of the electrocatalysts. ${ }^{2,3,6-10} \mathrm{Pt}$ catalyst is known to favour the undesirable dehydration pathway involving the generation of surface poisoning intermediate species CO. ${ }^{11}$ Such intermediate species actually blocks the adsorption of reactive formate species on the catalyst surface and slow down the electron transfer kinetics. The modification of Pt surface with surface adatom is known to facilitate the oxidation process by altering the reaction pathway. On the other hand, the Pd catalyst is known to favour the direct dehydrogenation pathway, which does not involve the formation of $\mathrm{CO} .{ }^{12}$ However, the activity and durability of Pd catalyst is not adequate enough for its utilization in DFAFC. In order to achieve high current density and durability, Pd-based bimetallic nanocatalysts and adatom modified Pd catalysts have been used. ${ }^{13-19}$ The electrocatalytic performance of these catalysts depends on the crystallographic orientation, composition, size and shape of the particles. ${ }^{15-17}$ 


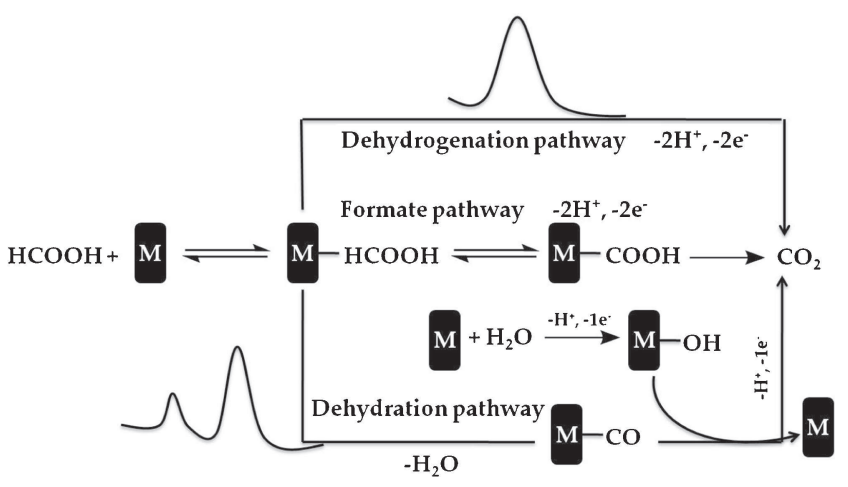

Figure 1. Possible reaction pathways for the electrochemical oxidation of formic acid on metal (M) surface.

Among the various nanoscale bimetallic nanocatalysts, Pt-Pd is demonstrated to have high electrocatalytic activity. ${ }^{18,19}$ The use of large amount of Pt actually increases the overall cost of the fuel cell and hence several efforts have been taken to minimize the amount of Pt content without compromising the electrocatalytic performance. ${ }^{20}$

The electrochemical route for the synthesis of nanoscale materials is a versatile approach. Both spatial and size control can be easily achieved by the fine tuning of electrochemical parameters. ${ }^{21}$ The major advantage associated with the electrochemical synthesis of nanoscale metal particles is that it does not require toxic reducing/stabilizing agents and sophisticated equipment. Moreover, the particles can be directly deposited on conducting platforms for microelectronic and micro fuel-cell applications. The co-deposition of $\mathrm{Pt}$ and $\mathrm{Pd}$ is a promising approach where the merits of both metals can be integrated to achieve enhanced electrocatalytic performance. Taking advantages of the electrochemical route, in this work the electrochemical co-deposition of Pt-Pd nanoparticles of different composition and the evaluation of their electrocatalytic performance towards oxidation of formic acid are described. Interestingly, we could tune the reaction pathway from dehydration to $\mathrm{CO}$-free dehydrogenation route by controlling the composition of Pt-Pd nanoparticles. The CO-free pathway is achieved with the bimetallic nanoparticle of ultralow Pt content. The electrocatalytic performance of bimetallic nanoparticle has been compared with the $\mathrm{Pt}$ and $\mathrm{Pd}$ nanoparticles obtained at the identical condition.

\section{Experimental}

\subsection{Materials}

$\mathrm{H}_{2} \mathrm{PtCl}_{6} \cdot 6 \mathrm{H}_{2} \mathrm{O}$ and $\mathrm{K}_{2} \mathrm{PdCl}_{4}$ were obtained from SigmaAldrich. Formic acid was purchased from Merck (India).
All other chemicals used in this study were of analytical grade (purity $\geq 99 \%$ ) and used as received. All the solutions were prepared with Milli-Q $(18 \mathrm{M} \Omega \mathrm{cm})$ water.

\subsection{Instrumentation}

The field emission scanning electron microscopic (FESEM) images of the nanoparticles were obtained with JEOL JEM 6700F electron microscope. The X-ray diffraction (XRD) analysis was performed with a Panalytical X'pert PRO high resolution XRD (PW 3040/60) unit using Ni-filtered $\mathrm{Cu} \mathrm{K} \alpha(\lambda=1.54 \AA)$ radiation. The overall atomic percentage of the alloy catalyst was measured with CAMECA sx-100 electron probe micro analyzer (EPMA). Electrochemical measurements were carried out in a two-compartment three-electrode cell using glassy carbon (GC) (surface area: $0.07 \mathrm{~cm}^{2}$ ) working ( $\mathrm{CH}$ Instruments, Texas, USA), Pt wire auxiliary, and $\mathrm{Ag} / \mathrm{AgCl}(3 \mathrm{M} \mathrm{KCl})$ reference electrodes. All electrochemical experiments were performed with Autolab potentiostat-galvanostat $(302 \mathrm{~N})$, using computer controlled GPES software. All the potentials are referred against standard hydrogen electrode (SHE) by adding a conversion factor of $0.197 \mathrm{~V}$.

\subsection{Synthesis of bimetallic nanoparticles}

Electrodeposition of Pt-Pd bimetallic nanostructures of $\mathrm{Pt}_{47} \mathrm{Pd}_{53}, \mathrm{Pt}_{7} \mathrm{Pd}_{93}$ and $\mathrm{Pt}_{4} \mathrm{Pd}_{96}$ were performed in 0.5 $\mathrm{M} \mathrm{H}_{2} \mathrm{SO}_{4}$ solution containing required molar ratio of $\mathrm{PtCl}_{6}^{2-}$ and $\mathrm{PdCl}_{4}^{2-}\left(\mathrm{PtCl}_{6}^{2-}: \mathrm{PdCl}_{4}^{2-}=1: 1,1: 15,1: 30\right)$ by stepping the potential from 1.1 to $0 \mathrm{~V}$ with a pulse width of 100s. The Pt and Pd nanoparticles were individually deposited under identical condition for the comparative study with Pt-Pd bimetallic nanoparticles. The electrodes were washed extensively with Millipore water after the deposition and used for further measurements. The electrochemically accessible surface area of the bimetallic nanoparticles was determined according to the literature procedure (figure $\mathrm{S} 1$ ).

\section{Results and Discussion}

\subsection{Characterization of nanoparticles}

The Pt-Pd bimetallic nanostructures of different atomic compositions have quasi spherical and aggregated flower-like shape with size ranging from of 80-200 nm (figure 2). The XRD profile shows a single diffraction peak at $2 \theta=39.86^{\circ}$ which is indexed to the (111) plane of the face centered cubic lattice of Pd (JCPDS: 46-1043), 
indicating the crystalline nature of the nanoparticles (figure 2d). The voltammetric profile of bimetallic nanoparticles shows the characteristic signature for the surface oxide formation and its reduction and hydrogen adsorption and desorption. The electrochemically accessible surface area of the nanoparticles was obtained according to the literature procedures ${ }^{22,23}$ (figure $\mathrm{S} 1$ ). The $\mathrm{Pt}_{47} \mathrm{Pd}_{53}, \mathrm{Pt}_{7} \mathrm{Pd}_{93}$ and $\mathrm{Pt}_{4} \mathrm{Pd}_{96}$ nanoparticles have the surface area of $0.166,0.135$ and $0.141 \mathrm{~cm}^{2}$, respectively.

\subsection{Electrochemical oxidation of formic acid}

The electrocatalytic performance of $\mathrm{Pt}, \mathrm{Pd}$ and $\mathrm{Pt}-\mathrm{Pd}$ bimetallic nanoparticles towards formic acid oxidation is shown in figure 3. On the Pt nanoparticle-based electrode, the oxidation in the forward scan shows a small peak $\sim 0.6 \mathrm{~V}$ (figure $3 \mathrm{a}$ ), corresponding to the oxidation of formic acid. Surface poisoning by in situ generated CO partially inhibits the oxidation. The sharp peak at $0.95 \mathrm{~V}$ corresponds to the anodic stripping of adsorbed $\mathrm{CO}$. The large anodic wave during the reverse sweep is due to the oxidation of formic acid at the CO-free clean Pt surface. ${ }^{13}$ On the other hand, the Pd nanoparticle-based electrode shows anodic peak $\sim 0.5 \mathrm{~V}$ during both forward and reverse sweeps for the oxidation of formic acid. The small hump $\sim 0.82 \mathrm{~V}$ could be due to the oxidative removal of $\mathrm{CO}$. The voltammetric features obtained for the $\mathrm{Pt}$ and $\mathrm{Pd}$ nanoparticles are in close agreement with the earlier literature. ${ }^{13,24}$ The voltammetric features for the oxidation of formic acid on $\mathrm{Pt}_{47} \mathrm{Pd}_{53}$ nanoparticles are very similar to that of $\mathrm{Pt}$ nanoparticles (figure $3 b$ ). The small broad peak at $\sim 0.6 \mathrm{~V}$ and the relatively sharp peak at $0.89 \mathrm{~V}$ in the forward scan are ascribed to the oxidation of formic acid and the stripping of adsorbed $\mathrm{CO}$, respectively. The negative shift in the formic acid oxidation and $\mathrm{CO}$ stripping peak position with respect to the Pt nanoparticle (figure 3a) can be attributed to the presence of Pd. The surface adsorption of in situ generated $\mathrm{CO}$ actually inhibits the oxidation process during the forward sweep. In the reverse sweep, the oxidative removal of poisonous $\mathrm{CO}$ at potential $>0.6 \mathrm{~V}$ activates the $\mathrm{Pt}_{47} \mathrm{Pd}_{53}$ surface. Consequently, a large anodic wave was obtained for the oxidation of formic acid during the reverse sweep.

Significant enhancement in the peak current and remarkable negative shift in the formic acid oxidation peak potential were observed while decreasing the $\mathrm{Pt}$ content of the catalyst. Surprisingly, $\sim 350 \mathrm{mV}$ negative shift in the formic acid oxidation peak potential and $\sim 2.6$ times enhancement in the peak current (forward sweep) were observed with $\mathrm{Pt}_{4} \mathrm{Pd}_{96}$ nanoparticles compared to $\mathrm{Pt}_{47} \mathrm{Pd}_{53}$ (figure $3 \mathrm{c}$ ). Such significant negative shift in the peak potential and enhancement in the peak current implies the decrease in the activation energy for the oxidation of formic acid. The onset potential for the oxidation of formic acid is $\sim 50 \mathrm{mV}$. To the best of our
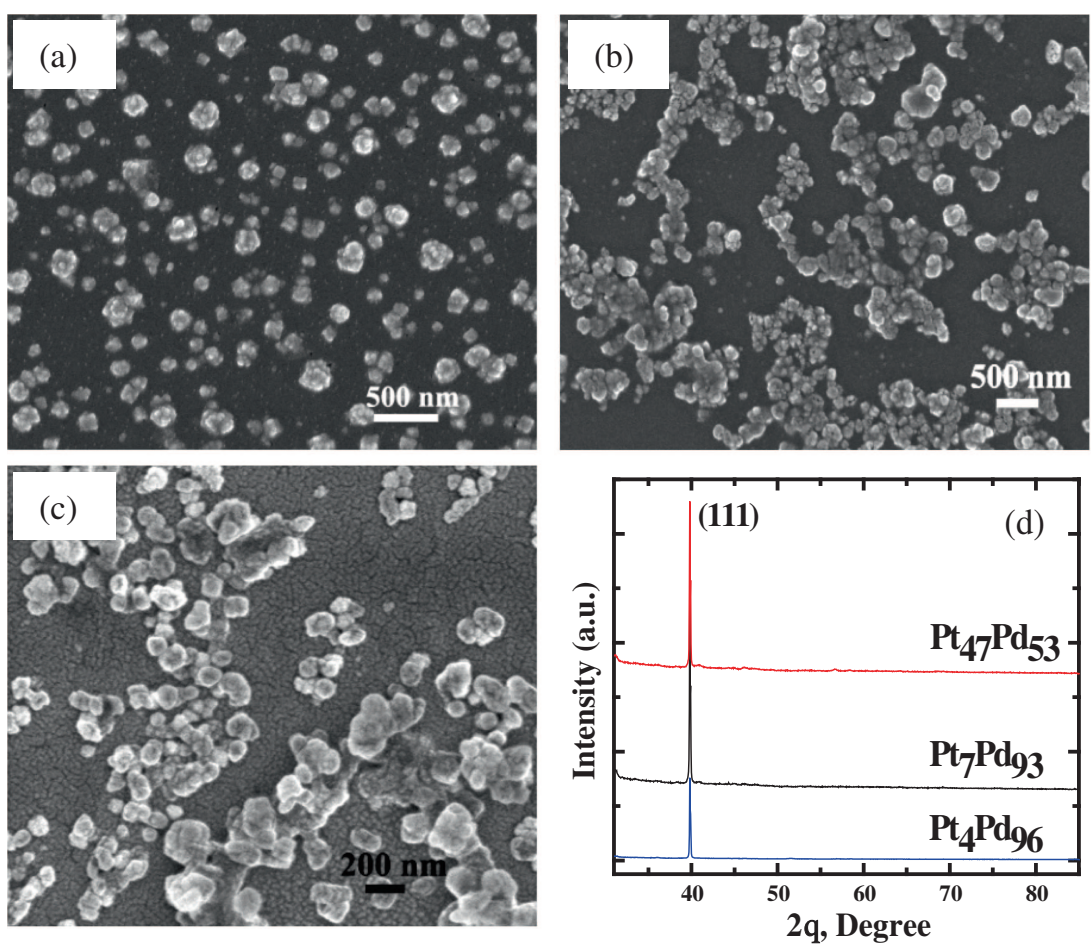

Figure 2. FESEM images of the electrodeposited (a) $\mathrm{Pt}_{4} \mathrm{Pd}_{96}$, (b) $\mathrm{Pt}_{47} \mathrm{Pd}_{53}$ and (c) $\mathrm{Pt}_{7} \mathrm{Pd}_{93}$ bimetallic nanoparticles. (d) XRD profiles of electrodeposited Pt-Pd bimetallic nanoparticles of different compositions. 

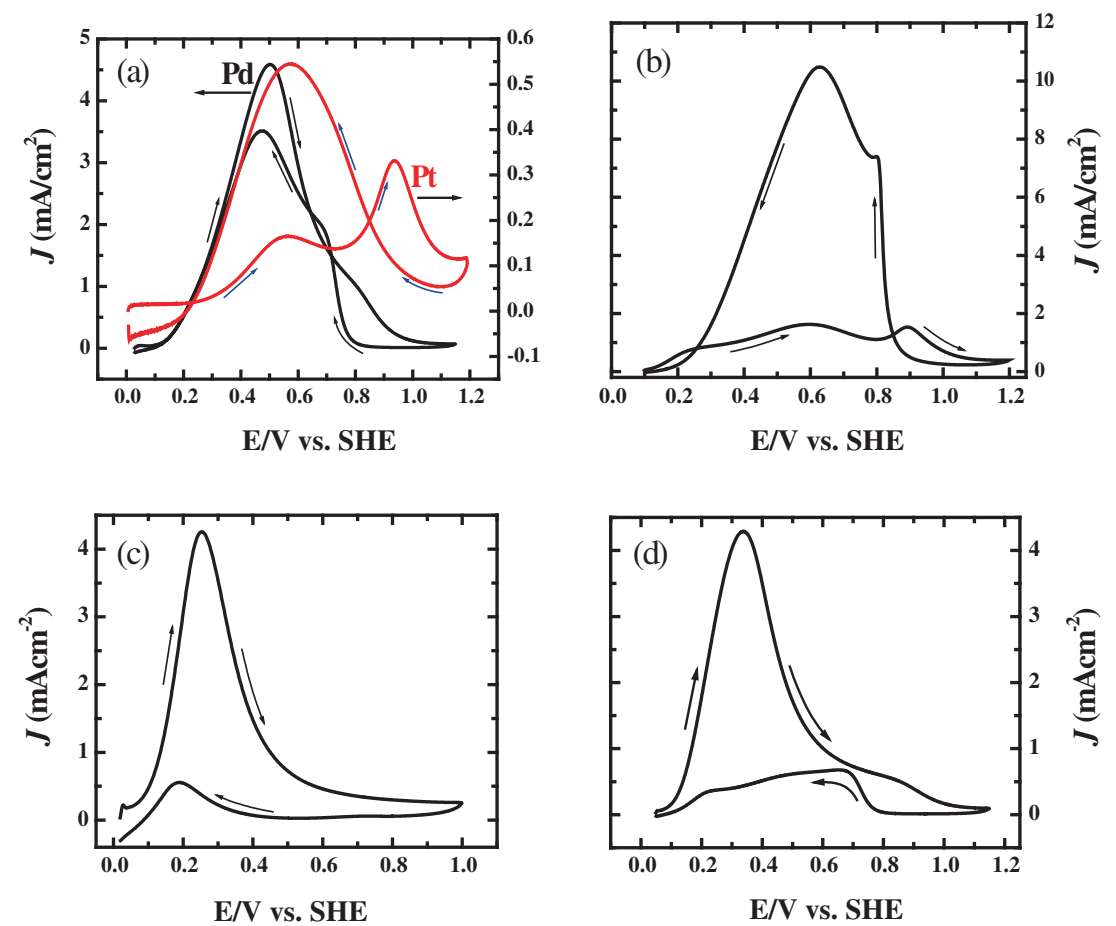

Figure 3. Cyclic voltammograms illustrating the electrocatalytic performance of (a) $\mathrm{Pt}$ and $\mathrm{Pd}$, (b) $\mathrm{Pt}_{47} \mathrm{Pd}_{53}$, (c) $\mathrm{Pt}_{4} \mathrm{Pd}_{96}$ and (d) $\mathrm{Pt}_{7} \mathrm{Pd}_{93}$ nanoparticles toward formic acid $(0.1 \mathrm{M})$ in $0.1 \mathrm{M}$ of $\mathrm{HClO}_{4}$. Scan rate: $50 \mathrm{mVs}^{-1}$.

knowledge this is the lowest potential reported so far in the literature (table S1). Among the existing catalysts, the Pd nanoparticles grown on cubic Pt nanocrystals show the onset potential of $\sim 0.1 \mathrm{~V}$ (RHE) with a peak potential of $0.27 \mathrm{~V}^{7}$ and the $\mathrm{Pd}$ adatom decorated $\mathrm{Pt}$ nanoparticles have the peak potential of $0.25 \mathrm{~V}$ with an onset potential of $\sim 0.1 \mathrm{~V}$ (RHE) ${ }^{13}$ for the oxidation of formic acid. Recently, the oxidation of formic acid on Sb-decorated octahedral Pt and Au@Pt dendrimer encapsulated nanoparticles with peak potential of $0.2 \mathrm{~V}$ (RHE) and $-0.2 \mathrm{~V}\left(\mathrm{Hg} / \mathrm{Hg}_{2} \mathrm{SO}_{4}\right)$ has been reported. ${ }^{25}$ The $\mathrm{Pt}_{7} \mathrm{Pd}_{93}$ nanoparticles show the anodic peak at $0.33 \mathrm{~V}$ and a very small hump at $\sim 0.85 \mathrm{~V}$ in the forward sweep (figure $3 \mathrm{~d}$ ). The small hump can be ascribed to the anodic stripping of adsorbed $\mathrm{CO}$. The oxidation potential is $\sim 330 \mathrm{mV}$ less positive than that of the $\mathrm{Pt}_{47} \mathrm{Pd}_{53}$ nanoparticles. Unlike the $\mathrm{Pt}_{4} \mathrm{Pd}_{96}$ nanoparticles, it shows small anodic peak $\sim 0.7 \mathrm{~V}$ during the reverse sweep though it is not very prominent (figure $3 \mathrm{~d}$ ). The magnitude of stripping peak current for adsorbed $\mathrm{CO}$ on $\mathrm{Pt}_{7} \mathrm{Pd}_{93}$ is significantly less with respect to the $\mathrm{Pt}_{47} \mathrm{Pd}_{53}$, signifying the change in reaction pathway while decreasing Pt content.

The careful analysis of the voltammetric profile for the oxidation of formic acid on the nanoparticles of different composition shows that the Pt content has strong influence on the oxidation. Significant negative shift in the peak potential and remarkable decrease in peak current were observed for the stripping of adsorbed $\mathrm{CO}$ while decreasing the Pt content. For instance, on the Pt nanoparticle, the stripping peak appears at the potential of $0.95 \mathrm{~V}$ and it shifts to $0.89 \mathrm{~V}$ and $0.84 \mathrm{~V}$ on $\mathrm{Pt}_{47} \mathrm{Pd}_{53}$ and $\mathrm{Pt}_{7} \mathrm{Pd}_{93}$ nanoparticles, respectively. No stripping signature was observed on $\mathrm{Pt}_{4} \mathrm{Pd}_{96}$ nanoparticles. The negative shift in the stripping peak potential implies the facile removal of adsorbed $\mathrm{CO}$ during the anodic process due to weak binding interaction. Moreover, the formic acid oxidation peak in the forward sweep shifts from $0.6 \mathrm{~V}\left(\mathrm{Pt}_{47} \mathrm{Pd}_{53}\right)$ to $0.34 \mathrm{~V}\left(\mathrm{Pt}_{7} \mathrm{Pd}_{93}\right)$ and then to $0.25 \mathrm{~V}\left(\mathrm{Pt}_{4} \mathrm{Pd}_{96}\right)$ while decreasing the Pt content, demonstrating that the formic acid oxidation is highly favourable on $\mathrm{Pt}_{4} \mathrm{Pd}_{96}$ nanoparticles. Such negative shift in the oxidation peak potential implies the facile electron transfer. The area normalized current density (table 1) for the oxidation of formic acid on the $\mathrm{Pt}_{4} \mathrm{Pd}_{96}$ at the potential of $0.25 \mathrm{~V}$ is $4.25 \mathrm{mAcm}^{-2}$ (for $0.1 \mathrm{M}$ formic acid), which is significantly higher than those of the other Pt-Pd and Pt-Ir catalysts ${ }^{26}$ (table S1). The ratio between the magnitudes of the peaks obtained during the forward and reverse sweep can provide knowledge on the reaction pathway. ${ }^{27}$ The $\mathrm{Pt}_{4} \mathrm{Pd}_{96}$ nanoparticles have the highest ratio of 7.418, which is significantly higher than $\mathrm{Pt}_{47} \mathrm{Pd}_{53}$ (0.156) and $\mathrm{Pd}$ (1.3) nanoparticlebased electrodes, suggesting that the oxidation mechanism on $\mathrm{Pt}_{4} \mathrm{Pd}_{96}$ nanoparticles involves the $\mathrm{CO}$-free dehydrogenation pathway. The voltammetric profile of 
Table 1. Catalytic performance of the bimetallic nanoparticles.

\begin{tabular}{lccccr}
\hline Catalyst & $\begin{array}{c}\text { ECSA } \\
\left(\mathrm{cm}^{2}\right)\end{array}$ & $\begin{array}{c}\text { Onset Pot. } \\
(\mathrm{V})\end{array}$ & $\begin{array}{c}E_{\mathrm{p}} \\
(\mathrm{V})\end{array}$ & $\begin{array}{c}\text { Peak current density* } \\
J\left(\mathrm{mAcm}{ }^{-2}\right)\end{array}$ & $\mathrm{I}_{\mathrm{f}} / \mathrm{I}_{\mathrm{b}}$ \\
\hline $\mathrm{Pt}_{4} \mathrm{Pd}_{96}$ & 0.141 & 0.036 & 0.251 & 4.251 & 7.18 \\
$\mathrm{Pt}_{7} \mathrm{Pd}_{93}$ & 0.135 & 0.057 & 0.336 & 4.288 & 5.92 \\
$\mathrm{Pt}_{47} \mathrm{Pd}_{53}$ & 0.166 & 0.255 & 0.595 & 1.638 & 0.15 \\
\hline * Current density was measured at the peak potential of the respective catalyst in the \\
forward sweep.
\end{tabular}

formic acid on the $\mathrm{Pt}_{4} \mathrm{Pd}_{96}$ nanoparticles does not show prominent peak during the cathodic sweep; the peak current in the reverse sweep is rather small. This may be associated with the surface composition/morphology of the nanoparticles, though the actual reason is not known at the present stage.

\subsection{Voltammetric stripping of in-situ generated CO}

In order to confirm CO-free pathway for the oxidation of formic acid on $\mathrm{Pt}_{4} \mathrm{Pd}_{96}$, the nanoparticle-based electrode was subjected to following experiments. The electrodes $\left(\mathrm{Pt}_{4} \mathrm{Pd}_{96}\right.$ and $\left.\mathrm{Pt}_{47} \mathrm{Pd}_{53}\right)$ were first pre-treated at their respective formic acid oxidation potential $\left[E_{\mathrm{p}}\right.$ $\left(\mathrm{Pt}_{4} \mathrm{Pd}_{96}\right)=0.25 \mathrm{~V}$ and $\left.E_{\mathrm{p}}\left(\mathrm{Pt}_{47} \mathrm{Pd}_{53}\right)=0.6 \mathrm{~V}\right]$ in Arsaturated $0.1 \mathrm{M} \mathrm{HClO}_{4}$ containing formic acid $(0.1 \mathrm{M})$ for $3 \mathrm{~min}$. These pre-treated electrodes were transferred to $0.5 \mathrm{M} \mathrm{H}_{2} \mathrm{SO}_{4}$ and the potential of the electrodes were scanned from 0.5 to $1.3 \mathrm{~V}$ (vs. SHE) for the anodic stripping of adsorbed $\mathrm{CO}$ (in-situ generated during the pre-treatment). As shown in figure $4 \mathrm{a}$, a well-defined anodic wave at the potential of $0.9 \mathrm{~V}$ corresponding to the anodic stripping of $\mathrm{CO}$ for the $\mathrm{Pt}_{47} \mathrm{Pd}_{53}$ nanoparticle was observed. The peak current significantly decreased in the second sweep. The peak potential $(0.9 \mathrm{~V})$ is very similar to that shown in figure $3 \mathrm{~b}$ for the anodic striping of $\mathrm{CO}$. On the other hand, no characteristic signature for the stripping of $\mathrm{CO}$ on $\mathrm{Pt}_{4} \mathrm{Pd}_{96}$ nanoparticles was observed (figure $4 \mathrm{~b}$ ), rationalizing that the $\mathrm{Pt}_{4} \mathrm{Pd}_{96}$ nanoparticle actually favour the dehydrogenation pathway for the oxidation of formic acid. The reaction pathway is tuned to dehydrogenation by changing the composition of the nanoparticles.

Chronoamperometric measurements were performed in order to evaluate the durability of the nanoparticles. The potential of the electrode was stepped from the onset potential to the peak potential and the steady state current was measured for one hour time (figure S2). Among the three bimetallic nanoparticles, $\mathrm{Pt}_{4} \mathrm{Pd}_{96}$ shows highest activity and durability. The deactivation rate on $\mathrm{Pt}_{4} \mathrm{Pd}_{96}$ nanoparticles was found to be $\sim 8 \% / 200 \mathrm{~s}$ in the first $30 \mathrm{~min}$ and no further significant change was noticed after $30 \mathrm{~min}$. The steady state current density at
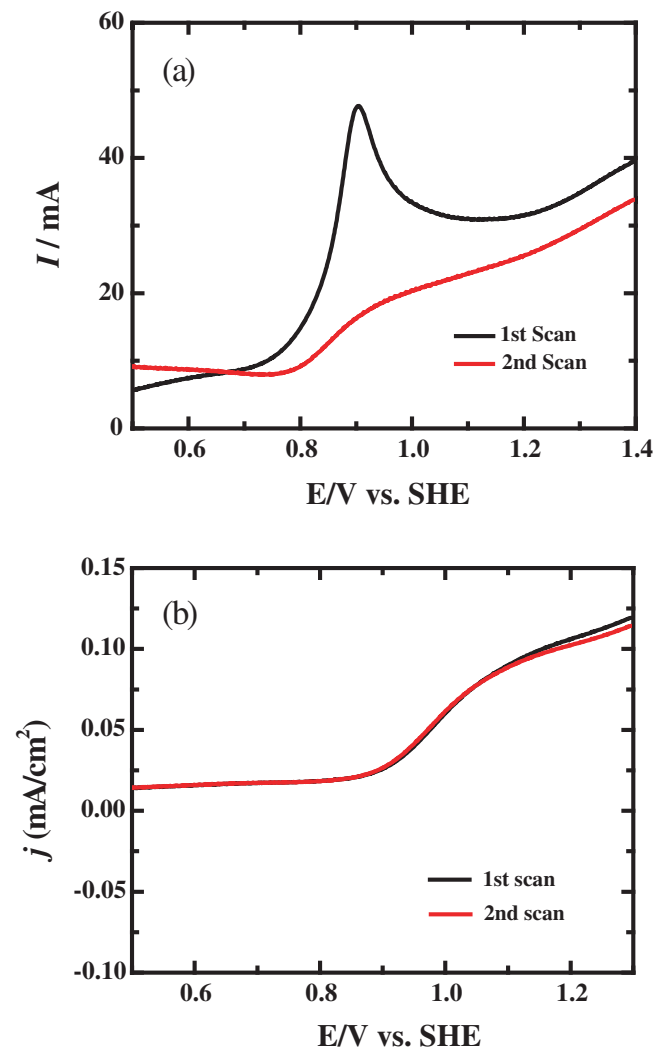

Figure 4. Linear sweep voltammograms of (a) $\mathrm{Pt}_{47} \mathrm{Pd}_{53}$ and (b) $\mathrm{Pt}_{4} \mathrm{Pd}_{96}$ nanoparticle-based electrodes in $0.5 \mathrm{M}$ $\mathrm{H}_{2} \mathrm{SO}_{4}$, that were pretreated at the potential of 0.6 and $0.25 \mathrm{~V}$, respectively for $3 \mathrm{~min}$ in Ar saturated $0.1 \mathrm{M} \mathrm{HClO}_{4}$ solution containing $0.1 \mathrm{M} \mathrm{HCOOH}$. Scan rate: $50 \mathrm{mVs}^{-1}$.

30 and 60 min remain same $\left(20 \mu \mathrm{Acm}^{-2}\right)$, highlighting the durability of the catalyst. The deactivation rate for the other nanoparticles is significantly high.

\subsection{Electrochemical impedance studies}

To further evaluate the electrocatalytic performance of bimetallic nanoparticles, potential-dependent electrochemical impedance measurements were performed. Representative potential-dependent Nyquist plot for the oxidation of formic acid on $\mathrm{Pt}_{4} \mathrm{Pd}_{96}$ and $\mathrm{Pt}_{47} \mathrm{Pd}_{53}$ nanoparticles are shown in figure 5. The impedance parameters were obtained by fitting the data with appropriate equivalent circuits (figure 5) and are tabulated in 

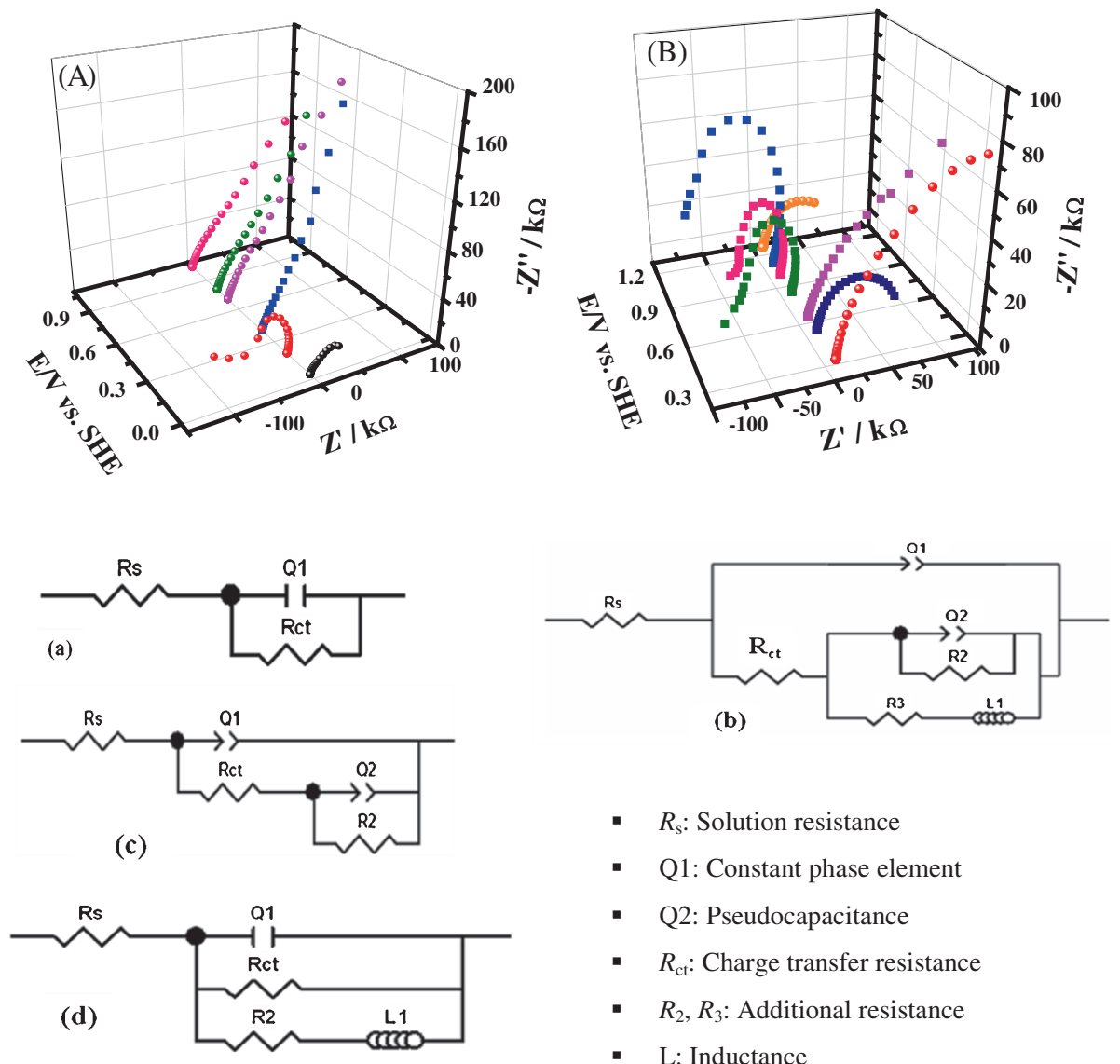

- $\quad R_{\mathrm{s}}$ : Solution resistance

- Q2: Pseudocapacitance

- $R_{\mathrm{ct}}$ : Charge transfer resistance

- $R_{2}, R_{3}$ : Additional resistance

- L: Inductance

Figure 5. Nyquist plot for the oxidation of formic acid $(0.1 \mathrm{M})$ as a function of applied potential on (A) $\mathrm{Pt}_{4} \mathrm{Pd}_{96}$ and (B) $\mathrm{Pt}_{47} \mathrm{Pd}_{53}$ nanoparticle-based electrodes in 0.1 $\mathrm{M} \mathrm{HClO}_{4}$. Equivalent circuits used to fit the impedance data are presented as 'a', 'b', 'c' and 'd'.

Table 2. Electrochemical impedance parameters obtained for Nyquist plot in figure 5A. ' $\mathrm{a}$ ' and ' $\mathrm{c}$ ' denote the equivalent circuit used to fit the data (equivalent circuits are given in figure 5).

\begin{tabular}{lccccccc}
\hline Pot. $(\mathrm{V})^{* *}$ & $\mathrm{R}_{\mathrm{s}}(\Omega)$ & $\mathrm{R}_{\mathrm{ct}}(\mathrm{k} \Omega)$ & $\mathrm{Q} 1(\mu \mathrm{Mho})$ & $\mathrm{R} 2(\mathrm{k} \Omega)$ & $\mathrm{Q} 2(\mu \mathrm{Mho})$ & $\mathrm{n} 1$ & $\mathrm{n} 2$ \\
\hline $0.03^{\mathrm{a}}$ & 51.1 & 45.5 & 151 & - & - & 0.85 & - \\
$0.2^{\mathrm{c}}$ & 52 & 2.1 & 31.9 & -50.7 & 12.2 & 0.81 & 0.93
\end{tabular}

**At $0.4,0.7,0.8$, and $1.0 \mathrm{~V}$ capacitive behaviour was observed.

table 2 and 3. In the equivalent circuits, $R_{\mathrm{S}}$ is the solution resistance and Q1 is the constant phase element (CPE). Generally, the electronic properties of the electrode cannot be described well with the double layer capacitance $\left(C_{\mathrm{dl}}\right)$ when the electrode surface is rather rough. In such situation, $C_{\mathrm{dl}}$ is substituted with $\mathrm{CPE}$ in the equivalent circuit. $\mathrm{CPE}$ is traditionally used to describe the non-ideal capacitive behaviour of the electrode. Mathematically, $\mathrm{CPE}=\mathrm{A}^{-1}(\mathrm{j} \omega)^{-\mathrm{n}}$, where $\mathrm{A}$ is a coefficient and $\omega$ is the frequency; the CPE become $\mathrm{C}_{\mathrm{dl}}$ when the value of $n$ approaches $1 .^{28}$ The charge transfer resistance is designated as $R_{\mathrm{ct}}$ whereas the resistance which is parallel to Q2 is designated as $R 2$. Q2 is associated with the pseudocapacitance. The resistance in series to the inductance is designated as $R 3$. The charge transfer resistance in the circuit related to the resistance of the electrode for charge transfer. On the other hand, the resistance $R 2$ and $R 3$ are associated with the adsorbate formation/removal from the electrode surface. The inductive loop of the impedance plot is modelled to pseudocapacitance in parallel with resistance or pseudoinductance in series with a resistance. ${ }^{28}$ In the case of $\mathrm{Pt}_{4} \mathrm{Pd}_{96}$, the impedance measurement performed at the foot of the voltammograms $(0.03 \mathrm{~V})$ shows a small semi-circle with $R_{\mathrm{ct}}$ value of $45.5 \mathrm{k} \Omega$. The impedance arc at the first quadrant indicates the presence of resistive and capacitive components, possibly due to the adsorption of formate species on the nanoparticle surface. 
Table 3. Electrochemical impedance parameters obtained for Nyquist plot in figure 5B. ' $a$ ', ' $b$ ' ' $c$ ' denote the equivalent circuit used to the fit the data (equivalent circuits are given in figure 5).

\begin{tabular}{lccccccccc}
\hline Pot. $(\mathrm{V})$ & $\mathrm{R}_{\mathrm{s}}(\Omega)$ & $\mathrm{R}_{\mathrm{ct}}(\mathrm{k} \Omega)$ & $\mathrm{Q} 1(\mu \mathrm{Mho})$ & $\mathrm{R} 2(\mathrm{k} \Omega)$ & $\mathrm{Q} 2(\mu \mathrm{Mho})$ & $\mathrm{R} 3(\mathrm{k} \Omega)$ & $\mathrm{L}(\mathrm{H})$ & $\mathrm{n} 1$ & $\mathrm{n} 2$ \\
\hline $0.2^{\mathrm{a}}$ & 52.9 & 183 & 24.7 & - & - & - & - & 0.82 & - \\
$0.4^{\mathrm{a}}$ & 47.4 & 62 & 10.1 & - & - & - & - & 0.82 & - \\
$0.5^{\mathrm{a}}$ & 45.7 & 146 & 12.8 & - & - & - & - & 0.81 & - \\
$0.7^{\mathrm{b}}$ & 50.1 & 40 & 2 & -80 & 60 & 10 & 500 & 0.71 & 0.73 \\
$0.85^{\mathrm{c}}$ & 48.5 & 9.5 & 8.02 & -48 & 3.67 & - & - & 0.83 & 0.72 \\
$0.95^{\mathrm{c}}$ & 48.7 & 11.2 & 9.65 & -71 & 11.2 & - & - & 0.82 & 0.76 \\
$1.15^{\mathrm{a}}$ & 47.6 & 55 & 11.3 & - & - & - & - & 0.85 & - \\
\hline
\end{tabular}

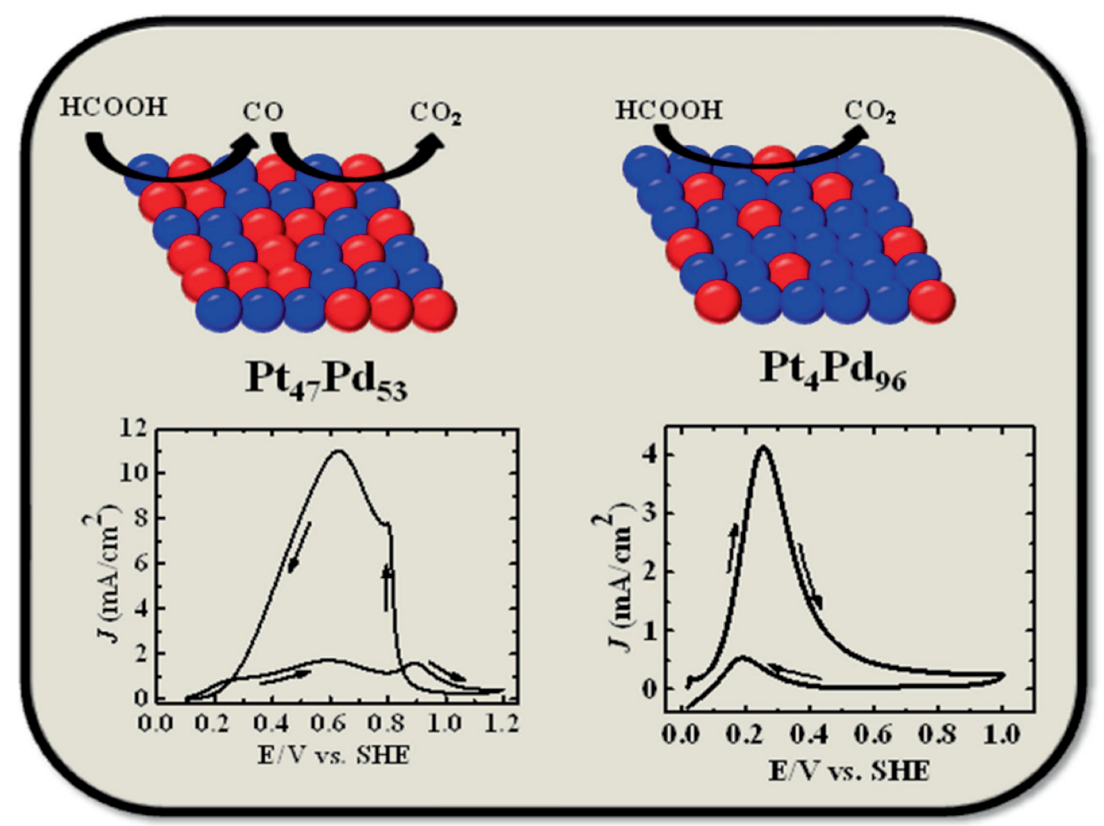

Figure 6. Possible reaction pathways for the oxidation of formic acid on $\mathrm{Pt}_{47} \mathrm{Pd}_{53}$ and $\mathrm{Pt}_{4} \mathrm{Pd}_{96}$.

The impedance arc moved to the second quadrant while further increasing the potential up to $0.2 \mathrm{~V}$. The appearance of the impedance arc in the second quadrant suggests the presence of an inductive component, presumably due to the formation of chemisorbed oxygen containing $-\mathrm{OH}$ like species. ${ }^{29}$ At more positive potentials the impedance plot is purely capacitive in nature, originating from the double layer capacitance. The absence of resistive components at higher potential implies the absence of $\mathrm{CO}$ adsorption/desorption. This is in good agreement with the voltammetric data shown in figure $3 \mathrm{c}$. The potential-dependent impedance profile supports the $\mathrm{CO}$-free pathway for the oxidation of formic acid.

The impedance behaviour of $\mathrm{Pt}_{47} \mathrm{Pd}_{53}$ nanoparticle is largely different from $\mathrm{Pt}_{4} \mathrm{Pd}_{96}$. The impedance profile shows that the formic acid oxidation on $\mathrm{Pt}_{47} \mathrm{Pd}_{53}$ involves the generation of $\mathrm{CO}$. At lower potential region $(0.2-0.5 \mathrm{~V})$ the impedance arc appears at the first quadrant(figure 5B). The $R_{\mathrm{ct}}$ at lower potential $(0.2-0.7 \mathrm{~V})$ is significantly high $(62-183 \mathrm{k} \Omega)$ indicating the adsorption of $\mathrm{CO}$ on the nanoparticle surface. As the potential arrives at $0.7 \mathrm{~V}$ a major change in the impedance spectra was observed with a negative resistance. The impedance spectra with loop at second and third quadrant during the electrooxidation process at more positive potentials can be ascribed as the reversible formation of oxide like species. ${ }^{29,30}$ The impedance arc at the potential $\geq 0.85 \mathrm{~V}$ appears in the second quadrant and the diameter of the arc significantly decreases while increasing the potential from $0.7 \mathrm{~V}$ to $0.85 \mathrm{~V}$. The appearance of the impedance arc at the second quadrant implies the presence of inductive component. The decrease in the $R_{\mathrm{ct}}$ value at more positive potential is actually due to the oxidative removal of CO. This is in agreement with the voltammetric profile presented in figure 3 . The impedance behaviour of $\mathrm{Pt}_{7} \mathrm{Pd}_{93}$ nanoparticles also illustrate the formation of CO-like species as evidenced from the large $R_{\mathrm{ct}}$ values (figure $\mathrm{S} 3$, table $\mathrm{S} 2$ ). The impedance profile for the oxidation of formic acid on 
$\mathrm{Pt}_{47} \mathrm{Pd}_{53}$ and $\mathrm{Pt}_{7} \mathrm{Pd}_{93}$ is closely similar to that of $\mathrm{Pt}$ and $\mathrm{Pd}$ nanoparticle-based electrodes (figure S4).

\subsection{Possible reaction pathway}

As described earlier, the electrochemical oxidation of formic acid in acidic solution on most of the metal electrodes can follow either the dehydration or dehydrogenation pathway (figure 1). Presence of parallel pathways cannot be ruled out. As expected, the bimetallic catalyst with more amount of Pt content actually follows the dehydration path, producing poisonous $\mathrm{CO}$ species. On the other hand, the bimetallic catalyst with less amount of Pt tends to favour the dehydrogenation rather than the dehydration pathway (figure 6). The Pd atoms in the bimetallic nanostructures actually inhibit the formation of surface poisoning $\mathrm{CO}$ in the low potential region and favour the oxidation at less positive potential. ${ }^{13}$ The superior performance of the $\mathrm{Pt}_{4} \mathrm{Pd}_{96}$ nanoparticles can be explained by considering the 'ensemble effect' and crystallographic orientation. The major contribution to the superior electrocatalytic performance of $\mathrm{Pt}_{4} \mathrm{Pd}_{96}$ originates from the 'ensemble effect'. The dehydration of formic acid to produce poisoning $\mathrm{CO}$ requires at least two adjacent Pt sites. ${ }^{27,31}$ The absence of such adjacent $\mathrm{Pt}$ sites would eventually suppress the formation of CO. ${ }^{32}$ The ultra-low amount of $\mathrm{Pt}$ in $\mathrm{Pt}_{4} \mathrm{Pd}_{96}$ nanoparticles can be considered as an impurity in a Pd rich environment and the separation of Pt sites by the surrounding Pd atoms would favour the dehydrogenation pathway rather than the dehydration pathway for the oxidation of formic acid. The marked change over of reaction pathway from dehydration to dehydrogenation while decreasing the Pt content can primarily be ascribed to the 'ensemble effect'. The absence of continuous Pt-Pd arrangement as depicted in figure 6 could be a reason for the CO-free pathway of formic acid oxidation. The voltammetric and impedance measurements support the dehydration pathway on the bimetallic catalyst with high Pt content $\left(\mathrm{Pt}_{47} \mathrm{Pd}_{53}\right)$.

\section{Conclusion}

The Pt-Pd bimetallic nanoparticles of different Pt content have been electrochemically synthesized. The oxidation of formic acid via CO-free pathway is achieved with the nanoparticles of ultra-low Pt content. The Pt content in bimetallic electrocatalyst actually determines the oxidation peak potential. The change of oxidation pathway from dehydration to dehydrogenation was observed while decreasing the Pt content is demonstrated for the first time. The 'ensemble effect' plays a key role in tuning the reaction pathway.

\section{Supplementary Information}

Voltammetric response of the nanoparticle-based electrode, chronoamperometric response illustrating the stability of the electrode towards formic acid oxidation, Nyquist plot for the oxidation of formic acid on $\mathrm{Pt}_{7} \mathrm{Pd}_{93}$, $\mathrm{Pt}$ and Pd nanoparticle-based electrodes, tables summarizing the previous literature on formic acid oxidation and impedance parameters are presented in the supplementary information available at www.ias.ac.in/ chemsci.

\section{Acknowledgements}

This work was financially supported by Department of Science and Technology, New Delhi.

\section{References}

1. Cheng T T and Gyenge E L $2009 \mathrm{~J}$. Appl. Electrochem. 391925

2. Rice C, Ha S, Masel R I, Waszczuk P, Wieckowski A and Barnard T 2002 J. Power Sources 11183

3. Choi J H, Jeong K J, Dong Y, Han J, Lim T H, Lee J S and Sung Y E 2006 J. Power Sources 16371

4. Liu H, Zhang J 2009 In Electrocatalysis of Direct Methanol Fuel Cells: From Fundamentals to Applications (Weinheim: Wiley-VCH)

5. Chen Y X, Heinen M, Jusys Z and Behm R J 2006 Angew. Chem. Int. Ed. 45981

6. Zhu Y, Khan Z and Masel R I 2005 J. Power Sources 13915

7. Zhou W J and Lee J Y 2007 Electrochem. Commun. 9 1725

8. Liu Z, Hong L, Tham M P, Lim T H and Jiang H 2006 J. Power Sources 161831

9. Larsen R, Ha S, Zakzeski J and Masel R I 2006 J. Power Sources 15778

10. Iyyamperumal R, Zhang L, Henkelman G and Crooks R M 2013 J. Am. Chem. Soc. 1355521

11. Rhee C K, Kim B J, Ham C, Kim Y J, Song K and Kwon K 2009 Langmuir 257140

12. Cui C H, Li H H, Cong H P, Yu S H and Tao F 2012 Chem. Commun. 4812062

13. Vidal-Iglesias F J, Solla-Gullón J, Herrero E, Aldaz A and Feliu J M 2010 Angew. Chem. Int. Ed. 496998

14. Leiva E, Iwasita T, Herrero E and Feliu J M 1997 Langmuir 136287

15. Vidal-Iglesias F J, Arán-Ais R M, Solla-Gullón J, Garnier E, Herrero E, Aldaz A and Feliu J M 2012 Phys. Chem. Chem. Phys. 1410258

16. Zhou W and Lee J Y 2008 J. Phys. Chem. C 1123789

17. Wang R, Liao S and Ji S 2008 J. Power Sources 180205

18. Lee H, Habas S E, Somorjai G A and Yang P $2008 \mathrm{~J}$. Am. Chem. Soc. 1305406

19. Lan F, Wang D, Lu S, Zhang J, Liang D, Peng S, Liu Y and Xiang Y 2013 J. Mater. Chem. A 11548

20. Chen G, Liao M, Yu B, Li Y, Wang D, You G, Zhong C J and Chen B H 2012 Int. J. Hydrogen Energ. 379959 
21. Corduneanu O, Diculescu V C, Chiorcea-Paquim A M and Oliveira-Brett A M 2008 J. Electroanal. Chem. 624 97

22. Trasatti S and Petrii A 1991 Pure. Appl. Chem. 63 711

23. Conrad H, Ertl G and Latta E E 1974 Surf. Sci. 41435

24. Wang Z B, Chu Y Y, Shao A, Zuo P J and Yin G P 2009 J. Power Sources 190336

25. Vidal-Iglesias F J, López-CuderoA, Solla-Gullón J and Feliu J M 2013 Angew.Chem. Int. Ed. 52964

26. Chen W and Chen S 2011 J. Mater. Chem. 219169
27. Ji X, Lee K T, Holden R, Zhang L, Zhang J, Botton G A, Couillard M and Nazar L F 2010 Nature Chem 2286

28. Chakraborty D, Chorkendorff I and Johannessen T 2006 J. Power Sources 1621010

29. Danaee I, Jafarian M, Forouzandeh F, Gobal F and Mahjani M G 2008 J. Phys. Chem. B 11215933

30. Melnick R E and Palmore G T R 2001 J. Phys. Chem. B 1051012

31. Park S, Xie Y and Weaver M J 2002 Langmuir 185792

32. Wang X M, Wang M E, Zhou D D and Xia Y Y 2011 Phys. Chem. Chem. Phys. 1313594 